\title{
A Marketing Strategy in a Closed-Loop Supply Chain with Loss-Averse Consumers
}

\author{
Bi-feng Liao $\circledast^{1,2}$ and Bang-yi Li ${ }^{1}$ \\ ${ }^{1}$ School of Economics and Management, Nanjing University of Aeronautics and Astronautics, Jiangsu, China \\ ${ }^{2}$ School of Mathematics and Information Science, Yantai University, Yantai, China
}

Correspondence should be addressed to Bi-feng Liao; ytliao1011@163.com

Received 10 May 2017; Accepted 7 November 2017; Published 10 January 2018

Academic Editor: Ibrahim Zeid

Copyright (C) 2018 Bi-feng Liao and Bang-yi Li. This is an open access article distributed under the Creative Commons Attribution License, which permits unrestricted use, distribution, and reproduction in any medium, provided the original work is properly cited.

\begin{abstract}
The importance of remanufacturing system has been extensively investigated in recent years. Taking into account the consumer valuation uncertainty and the demand uncertainty, this paper addresses the issue of closed-loop supply chain with remanufacturing by game theory. We consider two types of consumers in the market: loss-neutral consumers and loss-averse consumers. The lossneutral consumers are completely rational. The loss-averse consumers, on the other hand, are with losses being more painful than equal-sized gains being pleasant. When multichannel structure can be chosen, the manufacturer has three pricing strategies in direct market: (1) keeping the price high with a small discount, no customers choose the online store; (2) keeping the price high with a moderate discount, only the loss-neutral customers choose the online store; (3) keeping the price low with a big discount, all customers choose the online store. Consumers make up their decisive selections through comparing the price and channel attributes. We introduce utility function for analyzing the market demand and then identify the optimal pricing and channel strategy to maximize the manufacturer's profit. Finally, the rationality and validities of the proposed model are illustrated by numerical examples, and sensitivity analyses of the parameters are also presented.
\end{abstract}

\section{Introduction}

Nowadays, the importance of the environmental performance and sustainable development is being recognized. In order to reduce environmental pollution and enhance the resource utilization, we push forward the stable development of closed-loop supply chain systems with production remanufacturing. Remanufacturing recovers value from used products to bring the product to like-new condition. Examples from industry show that the quality of remanufactured products is as good as or better than that of the new products; hence they can be sold in the same market. In this paper, we assume that there is no distinction between a new and a remanufactured product.

Our paper relates to several streams of literature; we review them one by one in the following.

The research on the reverse logistics management issues for remanufactured products has received a considerable amount of attention in the past few years. We refer to
Fleischmann et al. [1] and Guide Jr. et al. [2] for complete reviews. Most of these research papers use game theory to model remanufacturing decisions [3-6], inventory control [7-9], and collection structures [10-13].

With the rapid development of Internet, a large number of firms have established avenues for selling direct to consumers (e.g., IBM, Nike, Kodak, and Dell). A manufacturer has the right to choose whatever distribution channels he desires and usually takes dual channel as a tool to create more demand. Consumers purchase products based on price and channel preference. Many works regard the Internet channel as the second distribution channel. Liu and Xiong [14] demonstrate the channel model where the new products are sold through the retailer, while the remanufactured products are sold through the direct channel. And then they obtain the price strategy. Wang et al. [15] model the channel structure for marketing the remanufactured products. They find that the subsidy can incentivize the remanufacturing activity in the sense of social welfare and environmental protection, while 
the manufacturer's optimal choice may be inefficient. Yan et al. [16] consider the model in which the manufacturer sells new products through the retailer while marketing remanufactured products through the online channel or a third party. The findings show that the manufacturer has less incentive to adopt the online channel because the profit may be worse than subcontracting to the third party. Wang et al. [17] deal with the channel structures for marketing the new and remanufactured products. They compare the three channel strategies and obtain the optimal distribution channel structure for new and remanufactured products. The results show that the dual channel may do harm to the retailer but benefit the consumers. Gao et al. [18] present a dual channel closed-loop supply chain model and analyze the effect of the consumer acceptance of Internet channel on pricing decisions. Giri et al. [19] study the closed-loop supply chain with dual channel and obtain analytically the pricing decisions under five different settings.

As the manufacturer is unlikely to predict all relevant factors, the demand usually does not match what is expected. Most papers studying the closed-loop supply chain in the operations management literature focus on demand uncertainty. Ahiska and Kurtul [20] consider such a system where product returns and demands are stochastic. They show that, in general, the demand risk reduces the system profits and always negatively impacts the manufacturer. Sun et al. [21] present a price-sensitive stochastic demand model based on the loss-averse retailer. With uncertain levels in the amount of raw material supplies and consumer market demands, Zeballons et al. [22] propose a multiperiod, multiproduct, and 10-layer network model. The effects of uncertain demand and supply on the network are analyzed. Li et al. [23] consider the remanufacturing and pricing decisions when both the remanufacturing yield and the demand for remanufactured products are random. They explore two typical decision strategies as first remanufacturing and then pricing and first pricing and then remanufacturing. And they obtain the remanufacturing quantity and selling price for each strategy.

On the other hand, most marketing researchers mainly focus on consumer valuation uncertainty when buying from the direct channel (e.g., [24-26]).

Our paper contributes to the literature related to prospect theory. The behavioral characteristic is of practice relevance and has a significant impact on the consumer's decision and the manufacturer's profit. A principle of behavioral economics is that many consumers are loss-averse. Lossaverse expression means the consumers whose perceived benefit of any gain is outweighed by the perceived cost of an equivalent loss [27]. As consumer valuation uncertainty plays a decisive role when they purchase a product, the loss-averse consumer has received a considerable amount of attention in recent years.

To the best of our knowledge, Sibly [28] incorporates the effect of consumer disposition toward a company in the model and draws the conclusion that the equilibrium price is rigid in the face of demand and cost shocks when the consumers are loss-averse. Heidhues and Koszegi [29] establish a model with loss-averse consumers. They embed these consumers in a market with a monopolistic seller for analyzing the demand and investigating the pricing strategy. Several definitions of loss-averse expression are put forward by Abdellaoui et al. [30]. They find the strong evidence of loss aversion at both the individual and the aggregate level. Under prospect theory, Won [31] presents a theoretical investigation on pioneering advantage based on the lossaverse effect. To develop effective market entry strategies, he suggests that companies should carefully analyze the loss-averse consumers and perceived uncertainty of their products. Kim and Lee [32] examine the profit maximizing firm behavior in the context of loss-averse consumers. They analyze the implications of loss aversion on the practice of product differentiation and price discrimination. Rosato [33] considers the problems of profit maximizing pricing and product-availability sales when the retailer sells two substitute products to loss-averse customers. He points out that the limited-availability strategy can manipulate customers into an ex ante purchase.

In this paper, firstly consumers are classified into two segments: loss-neutral (N) and loss-averse (L). Secondly the consumer valuation for direct channel and indirect channel is introduced and the consumer surplus is analyzed for different settings. Finally, the consumer choice is presented according to the consumer utility functions.

Our paper reveals that the standard deviation of consumer valuation, the loss-averse index, the acceptation of the direct channel, and the collection amount of the used products have a much larger effect on the manufacturer's profit, while the correlation of the two types of consumers does not have a significant effect on the profit. We also observe that the demand variability and the loss-averse degree become especially important for the manufacturer who needs to determine whether or not to introduce the direct channel.

The rest of the paper is organized as follows. Section 2 describes the model. By analyzing the consumer utility functions, we determine the consumer purchasing behavior and characterize the equilibria in Section 3. In Section 4, we compare the three strategies and conduct the sensitivity analysis. Finally in Sections 5 and 6, we present the computational results and offer brief conclusion, respectively.

\section{Model Setting}

Two marketing channels are considered in this paper: the traditional retailer channel (physical store) and the Internet channel (online store).

When a product first appeared on the market, it is hard for consumers to value it because of the lack of using information. If the products are available on the online store, it provides a virtual description with only the text graphics or symbols in the website. In this case, the consumers valuation is even uncertain. Let random variable $V$ represent consumer valuation with a density function $f\left(\mu_{v}, \sigma_{v}\right)$. To make further analysis easier, we assume $V$ follows a uniform distribution, which has a mean $\mu_{v}$ and a standard deviation $\sigma_{v}$. In order to extract the consumer surplus and not to drive the consumer away, a reasonable price $p$ should fall in the range $\left(\mu_{v}-\right.$ $\left.\sqrt{3} \sigma_{v}, \mu_{v}+\sqrt{3} \sigma_{v}\right)=\left(p_{l}, p_{h}\right)$. 
Consumer surplus is different depending on the consumer choice. We analyze it case by case.

If the consumer purchases a product in the physical store, the random variable is realized as $v$. For both type of consumers, utility equals surplus.

Since the consumer cannot obtain the use of smell, touch, and taste from the direct market, the consumer surplus may be negative. The utility for type $N$ consumers equals surplus, while for type $L$ consumers the utility functions are as follows.

$$
\text { Utility }= \begin{cases}\gamma * \text { surplus, } & \text { if surplus is negative } \\ \text { surplus, } & \text { otherwise, }\end{cases}
$$

where $\gamma>1$ indicates how averse a consumer is to loss, and the larger $\gamma$ shows that the consumer is more loss-averse.

Let $R$ denote a consumer purchasing from the physical store and $D$ represent the online store. The stochastic market demands of type $L$ and $N$ consumers denote by $Q_{L}$ and $Q_{N}$, respectively. They are jointly distributed as a bivariate normal distribution with expected values $\mu_{L}$ and $\mu_{N}$, standard deviations $\sigma_{L}$ and $\sigma_{N}$, and correlation coefficient $\rho \in(-1,1)$.

Throughout the paper, we will use the following notations. Let $Q$ denote the production of new products by manufacturer to meet the R-Channel, $Q_{D}$ denote the build-toorder production in the $D$-Channel, and $\theta$ denote consumer value discount for the $D$-Channel, and we characterize the return rate of the end of used products from the customers by $\tau(0<\tau<1)$. Symbol $c_{m}$ denotes the unit cost of manufacturing a new product, $c_{r}\left(c_{r}<c_{m}\right)$ denotes the unit cost of manufacturing an end of used product into a new one, and thus the average unit cost of manufacturing can be computed as $\bar{c}=(1-\tau) c_{m}+\tau c_{r}=c_{m}-\tau \Delta$, where $\Delta=c_{m}-c_{r}$ is the unit cost saving from reuse. $p$ is the retail price through the physical store. When the direct channel is introduced, a consumer pays the discount price $x p(0<x<$ 1) for the product; that is, $x p$ is the retail price through the Internet channel. The total cost of collection can be written as a function of the returned rate of the end of used products and is given by $C(\tau)=a \tau\left(Q+Q_{D}\right)$, where $\tau\left(Q+Q_{D}\right)$ is the total returned number from the customers. All of them can be remanufactured into new products.

For convenience, we use the notation $U_{i}^{j}$ as the expected utility of a type $i$ consumer when buying in channel $j$, where $i \in\{N, L\}$ and $j \in\{R, D\}$.

The expected utility functions are as follows:

$$
\begin{aligned}
U_{L}^{D} & =E(\theta V-x p)-(\gamma-1) \int_{p_{l}}^{x p / \theta}(x p-\theta v) f(v) d v \\
U_{N}^{D} & =E(\theta V-x p) \\
U_{L}^{R} & =E[\max (V-p, 0)] \\
U_{N}^{R} & =E[\max (V-p, 0)] .
\end{aligned}
$$

\section{Analysis and Results}

As a benchmark scenario, we start our analysis that focuses on the impact of the loss-averse segment. Our goal is to identify the conditions under which the introduction of online store is profitable.

Proposition 1. (1) If $x p>\theta \mu_{v}-\int_{p}^{p_{h}}(v-p) f(v) d v$, both type L and $N$ customers choose the R-Channel; that is, no customers choose the D-Channel.

(2) If $x p \leq \theta \mu_{v}-\int_{p}^{p_{h}}(v-p) f(v) d v$ and $x p+(\gamma-$ 1) $\int_{p_{l}}^{x p / \theta}(x p-\theta v) f(v) d v>\theta \mu_{v}-\int_{p}^{p_{h}}(v-p) f(v) d v$, only the type $N$ customers choose the D-Channel.

(3) If $x p+(\gamma-1) \int_{p_{l}}^{x p / \theta}(x p-\theta v) f(v) d v \leq \theta \mu_{v}-\int_{p}^{p_{h}}(v-$ p) $f(v) d v$, all customers choose the D-Channel.

Based on Proposition 1, we analyze the manufacturer's expected profit in the following three scenarios.

Case 1 (both type $L$ and $N$ customers choose the $R$-Channel (only $R$-Channel)). The demand via the $R$-Channel is $Q_{R}=$ $\bar{F}(p)\left(Q_{L}+Q_{N}\right)$. The random variable $Q_{R}$ has a normal distribution with the mean and standard deviation as follows:

$$
\begin{aligned}
\mu_{R} & =\bar{F}(p)\left(\mu_{L}+\mu_{N}\right) \\
\sigma_{R} & =\bar{F}(p)\left[\left(\sigma_{L}\right)^{2}+\left(\sigma_{N}\right)^{2}+2 \sigma_{L} \sigma_{N} \rho\right]^{1 / 2} .
\end{aligned}
$$

The expected profit of the manufacturer is

$$
\begin{aligned}
E \pi & =E_{Q_{R}}\left\{-\bar{c} Q-\delta Q+p \min \left(Q, Q_{R}\right)\right. \\
& \left.+s \max \left\{\left(Q-Q_{R}\right), 0\right\}-a \tau Q\right\} .
\end{aligned}
$$

To maximize the manufacturer's expected profit, it is well known that the optimal production is

$$
\begin{gathered}
Q^{1 *}=\bar{F}(p)\left(\mu_{L}+\mu_{N}\right)+\Phi^{-1}\left(\frac{p-\bar{c}-a \tau}{p-s}\right) \bar{F}(p) \\
\cdot\left[\left(\sigma_{L}\right)^{2}+\left(\sigma_{N}\right)^{2}+2 \sigma_{L} \sigma_{N} \rho\right]^{1 / 2}=u_{R}+e \sigma_{R},
\end{gathered}
$$

where $e=\Phi^{-1}((p-\bar{c}-a \tau) /(p-s)) ; \varphi(\cdot)$ and $\Phi(\cdot)$ are the density and cumulative function of the standard normal distribution, respectively.

Corollary 2 (the optimal production $Q^{1 *}$ increases with the return rate $\tau$ and correlation coefficient $\rho$ ). By substituting and rearranging we yield

$$
\begin{aligned}
& E \pi^{1 *}=(p-\bar{c}-a \tau) u_{R}-(p-s) \varphi(e) \sigma_{R} \\
& =(p-\bar{c}-a \tau) \bar{F}(p)\left(\mu_{L}+\mu_{N}\right) \\
& \quad-(p-s) \varphi(e) \bar{F}(p)\left[\left(\sigma_{L}\right)^{2}+\left(\sigma_{N}\right)^{2}+2 \sigma_{L} \sigma_{N} \rho\right]^{1 / 2} .
\end{aligned}
$$

Case 2 (only the type $N$ customers choose the $D$-Channel (both channels)). When the manufacturer offers a price discount such that the type $N$ consumers buy in $D$-Channel, while the $L$ consumers buy in $R$-Channel, then, the demands during the two channel structures are $Q_{D}=Q_{N}$ and $Q_{R}=$ $\bar{F}(p) Q_{L}$, respectively. 
Since random variables $Q_{N}$ and $Q_{L}$ follow a bivariate normal distribution, $Q_{D}$ and $Q_{R}$ also have a bivariate normal distribution. The means that standard deviations and correlation coefficient are as follows:

$$
\begin{aligned}
\mu_{D} & =\mu_{N}, \\
\mu_{R}^{\prime} & =\bar{F}(p) \mu_{L} \\
\sigma_{D} & =\sigma_{N}, \\
\sigma_{R}^{\prime} & =\bar{F}(p) \sigma_{L}, \\
\operatorname{corr}\left(Q_{D}, Q_{R}\right) & =\rho .
\end{aligned}
$$

Note that the direct market has the features that consumers submit the orders and they will not receive the product immediately. The manufacturer may provide distribution services a few days later. Thus the delivery time of goods to customers provides a certain buffer time for manufacturer. To reduce the risks, the build-to-order production is more effective for manufacturer in such market circumstance. In this model, the manufacturer lowers the loss of overstock and shortage to zero, while in the physical shop the consumption will lead to the result that purchasing of products does not originate from advertisement anymore but from the product itself. The proper stocking level can ensure that the customer shopping experience is easy and fun. At the end of the selling season, the manufacturer inevitably faces the losses of unmarketable goods or sales.

Then, the expected profit can be expressed as follows:

$$
\begin{aligned}
E \pi & =E_{Q_{D}, Q_{R}}\left\{(x p-\bar{c}) Q_{D}+p \min \left(Q, Q_{R}\right)\right. \\
& \left.+s \max \left\{\left(Q-Q_{R}\right), 0\right\}-\bar{c} Q-a \tau\left(Q+Q_{D}\right)\right\} .
\end{aligned}
$$

The optimal production and expected profit are

$$
\begin{aligned}
Q^{2 *}= & \bar{F}(p) \mu_{L}+\Phi^{-1}\left(\frac{p-\bar{c}-a \tau}{p-s}\right) \bar{F}(p) \sigma_{L} \\
= & \mu_{R}^{\prime}+e \sigma_{R}^{\prime} \\
E \pi^{2 *}= & (x p-\bar{c}) \mu_{D}+(p-\bar{c}-A \tau) u_{R}^{\prime} \\
& -(p-s) \varphi(e) \sigma_{R}^{\prime} \\
= & (x p-\bar{c}) \mu_{N}+(p-\bar{c}-a \tau) \bar{F}(p) \mu_{L} \\
& -(p-s) \varphi(e) \bar{F}(p) \sigma_{L} .
\end{aligned}
$$

In order to attract consumers to turn to D-Channel, we know that the price $x p$ cannot be larger than $\theta \mu_{v}-\int_{p}^{p_{h}}(v-$ p) $f(v) d v$ from Proposition 1 . The manufacturer's objective is to maximize his profit, so he provide the price $x p=\theta \mu_{v}-$ $\int_{p}^{p_{h}}(v-p) f(v) d v$

We transform the profit from the $D$-Channel as follows:

$$
\begin{aligned}
(x p-\bar{c}) \mu_{N} & =\left(\theta \mu_{v}-\bar{c}-\int_{p}^{p_{h}}(v-p) f(v) d v\right) \mu_{N} \\
& =(p-\bar{c}) \bar{F}(p) \mu_{N}+(p-\bar{c}) F(p) \mu_{N}
\end{aligned}
$$

$$
\begin{aligned}
& -(1-\theta) \mu_{v} \mu_{N}-\int_{p_{l}}^{p}(p-v) f(v) d v \\
= & (p-\bar{c}) \bar{F}(p) \mu_{N}-(1-\theta) \mu_{v} \mu_{N} \\
& +\mu_{N} \int_{p_{l}}^{p}(v-\bar{c}) f(v) d v .
\end{aligned}
$$

Therefore, we have the following profit expression:

$$
\begin{aligned}
E \pi^{2 *}= & (p-\bar{c}) \bar{F}(p) \mu_{N}-(1-\theta) \mu_{v} \mu_{N} \\
& +\mu_{N} \int_{p_{l}}^{p}(v-\bar{c}) f(v) d v \\
& +(p-\bar{c}-a \tau) \bar{F}(p) \mu_{L} \\
& -(p-s) \varphi(e) \bar{F}(p) \sigma_{L} .
\end{aligned}
$$

Case 3 (all customers choose the D-Channel (only $D$ Channel)). Because the price of the product is different, the demand channel is also very different. When the manufacturer offers a very low price in the $D$-Channel, both type $N$ and type $L$ consumers buy through $D$-Channel. Hence, the demand is $Q_{D}=Q_{N}+Q_{L}$.

During the selling period, the manufacturer's production of the goods just fits in with the needs of the society.

Then the expected profit is

$$
E \pi=E\left\{(x p-\bar{c}) Q_{D}-a \tau Q_{D}\right\} .
$$

The optimal profit can be expressed as follows:

$$
E \pi^{3 *}=(x p-\bar{c}-A \tau)\left(\mu_{N}+\mu_{L}\right) .
$$

According to Proposition 1, the price in the $D$-Channel should satisfy $x p+(\gamma-1) \int_{p_{l}}^{x p / \theta}(x p-\theta v) f(v) d v \leq \theta \mu_{v}-$ $\int_{p}^{p_{h}}(v-p) f(v) d v$. In order to maximize the expected profit, the manufacturer offers a price to satisfy

$$
\begin{gathered}
x p+(\gamma-1) \int_{p_{l}}^{x p / \theta}(x p-\theta v) f(v) d v \\
=\theta \mu_{v}-\int_{p}^{p_{h}}(v-p) f(v) d v .
\end{gathered}
$$

Corollary 3 (the optimal price of D-Channel in Case 3 is always smaller than in Case 2). To attract both type $L$ and $N$ consumers to buy in D-Channel, the manufacturer has to provide a deeper price discount. It is intuitive since the type $L$ consumers require a lower price than type $N$ consumers as the motivation to buy in D-Channel.

Remark 4.

$$
\begin{aligned}
& \frac{\partial x p}{\partial \theta}=\frac{\mu_{v}+(\gamma-1) \int_{p_{l}}^{x p / \theta} v f(v) d v}{1+(\gamma-1) F(x p / \theta)}>0 \\
& \frac{\partial x p}{\partial \gamma}=-\frac{\int_{p_{l}}^{x p / \theta}(x p-\theta v) f(v) d v}{1+(\gamma-1) F(x p / \theta)}<0 .
\end{aligned}
$$


With an increase in the acceptance of the D-Channel, the possibility of the type of loss-averse consumers buying from $D$-Channel will increase. But, on the contrary, as the consumers become more loss-averse, the purchase action of consumers will greatly decrease. The manufacturer should attract more consumers to buy products from $D$-Channel by decreasing the price.

\section{Sensibility Analysis}

By comparing the optimal profits from the above three cases, the manufacturer can make the channel decisions. We show the effects of loss-averse and other parameters on consumers' equilibrium strategies and the manufacturer's pricing decisions.

Let $\Delta \pi_{21}$ denote the profit difference between the Cases 2 and 1; that is, $\Delta \pi_{21}=E \pi^{2 *}-E \pi^{1 *}$. From the optimal profit expressions, we have

$$
\begin{gathered}
\Delta \pi_{21}=\left(\int_{p_{l}}^{p}(v-\bar{c}-a \tau) f(v) d v-(1-\theta) \mu_{v}+a \tau\right) \\
\cdot \mu_{N}+(p-s) \varphi(e) \bar{F}(p) \\
\cdot\left(\left[\left(\sigma_{L}\right)^{2}+\left(\sigma_{N}\right)^{2}+2 \sigma_{L} \sigma_{N} \rho\right]^{1 / 2}-\sigma_{L}\right),
\end{gathered}
$$

where $\bar{c}=(1-\tau) c_{m}+\tau c_{r}=c_{m}-\tau \Delta$.

Proposition 5. $\Delta \pi_{21}$ has the following features.

(1) $\Delta \pi_{21}$ is a concave function of $\mu_{v}$. When $\mu_{v}<\bar{c} / \theta$, the $D$-Channel hurts the manufacturer in profit.

(2) $\Delta \pi_{21}$ increases with $\theta$. When $\theta$ is more than a certain threshold, the D-Channel favors the manufacturer in profit. A higher willingness to pay for D-Channel favors D-Channel more than R-Channel.

(3) $\Delta \pi_{21}$ increases in $\tau$.

Proof. (1) To prove that the expression $\Delta \pi_{21}$ is a concave function of $\mu_{v}$, we take the second derivative of $\Delta \pi_{21}$ with respect to $\mu_{v}$.

$$
\begin{aligned}
& \frac{\partial \Delta \pi_{21}}{\partial \mu_{v}}=\frac{1}{2 \sqrt{3} \sigma_{v}}\left(\left(-\left(\mu_{v}-\sqrt{3} \sigma_{v}-\bar{c}\right)\right.\right. \\
& \left.-2 \sqrt{3} \sigma_{v}(1-\theta)-(h-\delta-A \tau)\right) \mu_{N}+(p+h-s) \\
& \left.\cdot \varphi(e)\left(\left[\left(\sigma_{L}\right)^{2}+\left(\sigma_{N}\right)^{2}+2 \sigma_{L} \sigma_{N} \rho\right]^{1 / 2}-\sigma_{L}\right)\right) \\
& \frac{\partial^{2} \Delta \pi_{21}}{\partial \mu_{v}^{2}}=-\frac{1}{2 \sqrt{3} \sigma_{v}} \mu_{N}<0 .
\end{aligned}
$$

Denote $A=\left(\int_{p_{l}}^{p}(v-\bar{c}-a \tau) f(v) d v-(1-\theta) \mu_{v}+a \tau\right) \mu_{N}$ and $B=(p-s) \varphi(e) \bar{F}(p)\left(\left[\left(\sigma_{L}\right)^{2}+\left(\sigma_{N}\right)^{2}+2 \sigma_{L} \sigma_{N} \rho\right]^{1 / 2}-\sigma_{L}\right)$. Part $B$ increases in $\mu_{v}$ and is always nonnegative.

It is easily to see that $A$ increases in $\mu_{v}$ if $\mu_{v}<\bar{c}+a \tau-$ $\sqrt{3}(1-2 \theta) \sigma_{v}$ and decreases in $\mu_{v}$ if $\mu_{v}>\bar{c}+a \tau-\sqrt{3}(1-2 \theta) \sigma_{v}$.

When $\mu_{v}=p-\sqrt{3} \sigma_{v}$ and $p<\bar{c} / \theta+\sqrt{3} \sigma_{v}$, that is, $\mu_{v}<\bar{c} / \theta$, we infer $A<0$, and $B=0$. Therefore we have $\Delta \pi_{21}=A+$
$B<0$. It shows that the $D$-Channel hurts the manufacturer in profit.

When $\mu_{v}=p+\sqrt{3} \sigma_{v}$ and $p+\sqrt{3} \sigma_{v}<a \tau /(1-\theta)$, the first part is positive, and the second part is greater than zero for any $\mu_{v}$, so the manufacturer benefits from the $D$-Channel.

From the above analysis, we know that $\Delta \pi_{21}$ changes from negative to positive. So there exists a threshold $\mu$ such that $\Delta \pi_{21}\left(u_{v}=u\right)=0$.

Furthermore, when $\mu_{v} \in\left(p-\sqrt{3} \sigma_{v}, \mu\right)$, the manufacture should not open the $D$-Channel and only sell in the $R$ Channel. When $\mu_{v} \in\left(\mu, p+\sqrt{3} \sigma_{v}\right)$, the $D$-Channel favors the manufacturer in profit. The manufacturer should set a discount to attract the price-sensitive consumers to purchase over the $D$-Channel.

Differentiating $\Delta \pi_{21}$ with respect to $\theta$ and $\tau$, we can get the other two conclusions in Proposition 5.

After some algebra, $\Delta \pi_{31}$ and $\Delta \pi_{32}$ are obtained as the following expressions:

$$
\begin{aligned}
& \Delta \pi_{31}=\left(\int_{p_{l}}^{p}(v-\bar{c}-a \tau) f(v) d v-(1-\theta) \mu_{v}\right. \\
& \left.-(\gamma-1) \int_{p_{l}}^{x p / \theta}(x p-\theta v) f(v) d v\right)\left(\mu_{N}+\mu_{L}\right) \\
& \quad+(p-s) \varphi(e) \bar{F}(p)\left[\left(\sigma_{L}\right)^{2}+\left(\sigma_{N}\right)^{2}+2 \sigma_{L} \sigma_{N} \rho\right]^{1 / 2} \\
& \Delta \pi_{32}=\left(\int_{p_{l}}^{p}(v-\bar{c}-a \tau) f(v) d v-(1-\theta) \mu_{v}\right. \\
& \left.-(\gamma-1) \int_{p_{l}}^{x p / \theta}(x p-\theta v) f(v) d v\right) \mu_{L}+(p-s) \\
& \cdot \varphi(e) \bar{F}(p) \sigma_{L}-a \tau \mu_{N}-(\gamma-1) \\
& \cdot \int_{p_{l}}^{x p / \theta}(x p-\theta v) f(v) d v * \mu_{N} .
\end{aligned}
$$

Proposition 6. (1) $\Delta \pi_{31}$ increases in $\rho$ and $\theta$.

(2) $\Delta \pi_{31}$ decreases in $\gamma$.

Proof.

$$
\begin{aligned}
\frac{\partial \Delta \pi_{31}}{\partial \rho}= & \frac{\sigma_{L} \sigma_{N}}{\left[\left(\sigma_{L}\right)^{2}+\left(\sigma_{N}\right)^{2}+2 \sigma_{L} \sigma_{N} \rho\right]^{1 / 2}}>0 \\
\frac{\partial \Delta \pi_{31}}{\partial \theta}= & \mu_{v}+(\gamma-1) \int_{p_{l}}^{x p / \theta} v f(v) d v>0 \\
\frac{\partial \Delta \pi_{31}}{\partial \gamma}= & -\int_{p_{l}}^{x p / \theta}(x p-\theta v) f(v) d v \\
& -(\gamma-1) \frac{\partial x p}{\partial \gamma} F\left(\frac{x p}{\theta}\right) \\
= & -\int_{p_{l}}^{x p / \theta}(x p-\theta v) f(v) d v
\end{aligned}
$$




$$
\begin{aligned}
& +(\gamma-1) F\left(\frac{x p}{\theta}\right) \frac{\int_{p_{l}}^{x p / \theta}(x p-\theta v) f(v) d v}{1+(\gamma-1) F(x p / \theta)} \\
& =-\frac{\int_{p_{l}}^{x p / \theta}(x p-\theta v) f(v) d v}{1+(\gamma-1) F(x p / \theta)}<0 .
\end{aligned}
$$

Proposition 7. (1) $\Delta \pi_{32}$ increases in $\sigma_{L}$ and $\theta$.

(2) $\Delta \pi_{32}$ decreases in $\mu_{N}$ and $\gamma$.

Through differentiating $\Delta \pi_{32}$ with respect to $\sigma_{L}, \theta, \mu_{N}$, and $\gamma$, we can easily get the proposition.

The manufacturer can compare Cases 2 and 3 by checking the sign of $\Delta \pi_{32}$. If $\Delta \pi_{32}>0$, Case 2 is dominated by Case 3 , and the manufacturer chooses strategy 3. Otherwise, Case 2 should be followed.

In view of the complex expressions $\Delta \pi_{31}$ and $\Delta \pi_{32}$, we handle them by numerical analysis.

\section{Numerical Experiments}

In this section, we examine how the manufacturer's profit changes with the various parameter values such as consumer loss-averse degree, correlation, the collection rate, the deviation of consumer valuation, and the willingness to pay for D-Channel.

The parameter values used in the numerical tests are as follows: $p=\$ 100, c_{n}=\$ 60, c_{r}=\$ 20, a=\$ 5, s=\$ 10, u_{N}=$ $u_{L}=20, \sigma_{N}=\sigma_{L}=2$, and $u_{v}=70$. Also initially, $\theta=0.7$, $y=2, \sigma_{v}=20, \tau=0.7$, and $\rho=0.4$. The curve with squares in Figures $1-5$ represents the profit from the $D$-Channel. The curve with asterisks represents the profit from the $R$-Channel. The third curve illustrates the profit from both channels.

Figure 1 illustrates the optimal profit of the three cases. We can see the impact of $\theta$ on the manufacturer's profit. It appears that both channels are always dominated by the others. The possibility of consumers buying products increases with the acceptance of the $D$-Channel. So the profit will increase. Therefore, the manufacture follows $D$-Channel by offing a higher price discount than both channels. And when the acceptance of the $D$-Channel is small, the manufacture favors the $R$-Channel. Only the acceptance reaches a certain degree, and the $D$-Channel would be a lucrative market.

From Figure 2 we can see that the $D$-Channel generates the highest profit when the standard deviation is small. This is because when the consumers' valuation is less variable, the possibility of realizing negative surplus is lower. It really shows that a small price discount can attract both types of consumers turning to D-Channel. Therefore, the manufacturer should favor only $D$-Channel when $\sigma_{v}$ is small.

For these parameter values, Figure 3 illustrates that the profit from $D$-Channel decreases sharply with the increase of the degree of loss aversion. It is said that if the consumers are more loss-averse, the manufacturer will provide the price lower enough to attract consumers to buy products, which makes the profit decrease. The curve with squares is above

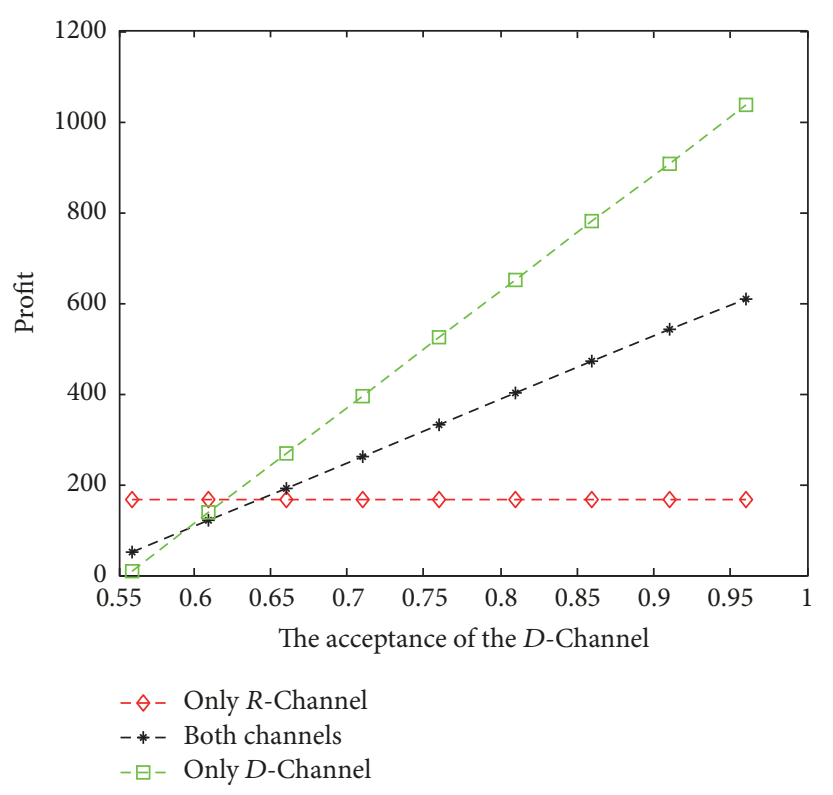

FIgURE 1: The effect of the acceptance of $D$-Channel on profits.

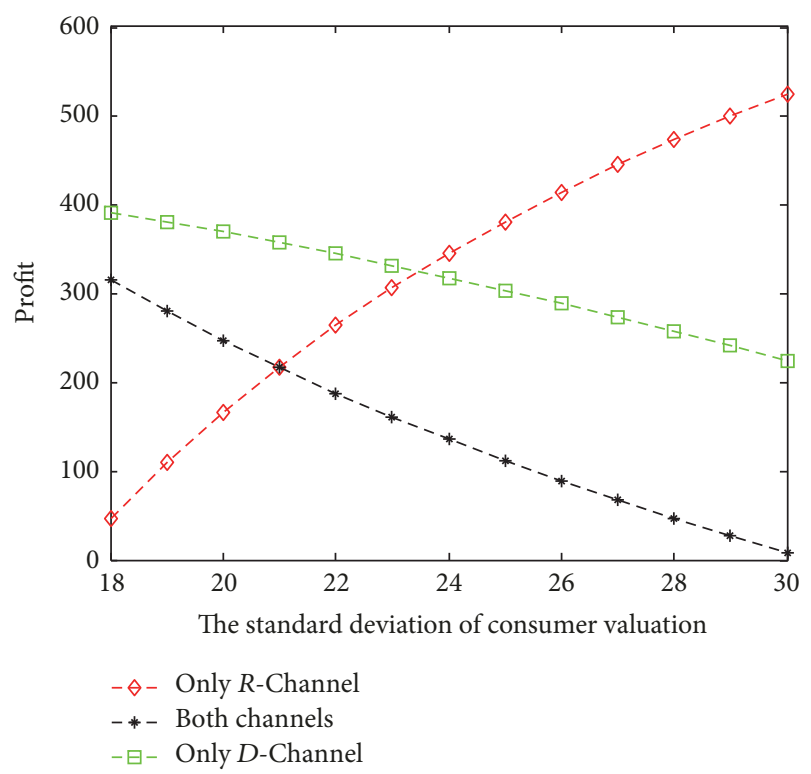

FIGURE 2: The effect of the standard deviation of consumer valuation on profits.

the other two curves when the loss-averse degree is small; that is, $D$-Channel generates the most profits when compared with the others. So, the manufacturer should only open the $D$-Channel if the consumers are less loss-averse. This is because it is easy to motivate both types of consumers to buy through $D$-Channel when the loss-averse index is small. If the consumer loss-averse index is relatively higher, the manufacturer should offer a lower price to attract consumers to buy by $D$-Channel. In order to generate more profit, the manufacturer chooses to introduce both channels.

We can see from Figure 4 that the profits increase sharply with the increase of the collection rate. The manufacturer 


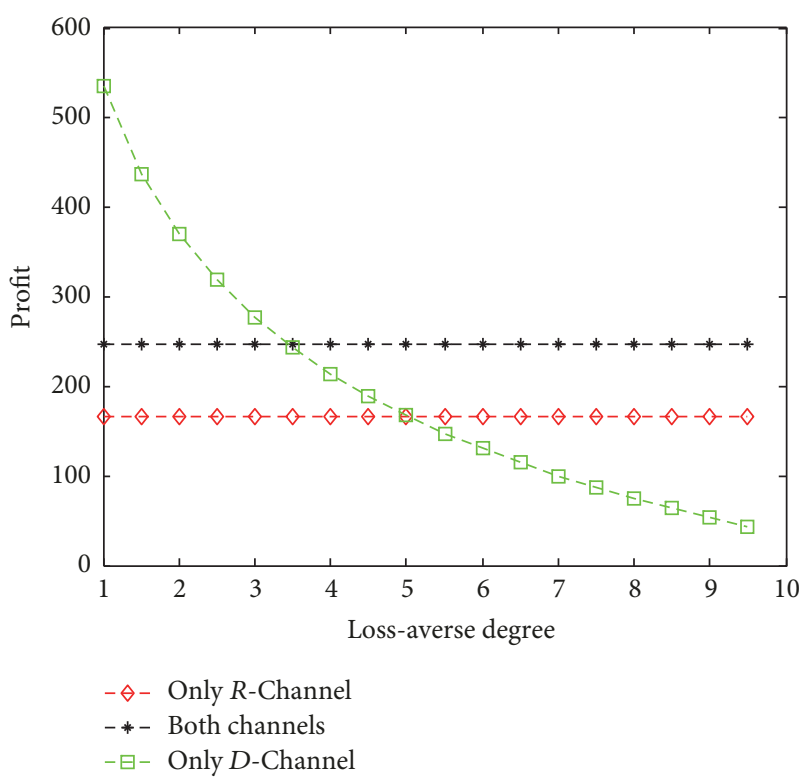

Figure 3: The effect of the consumer loss-averse degree on profits.

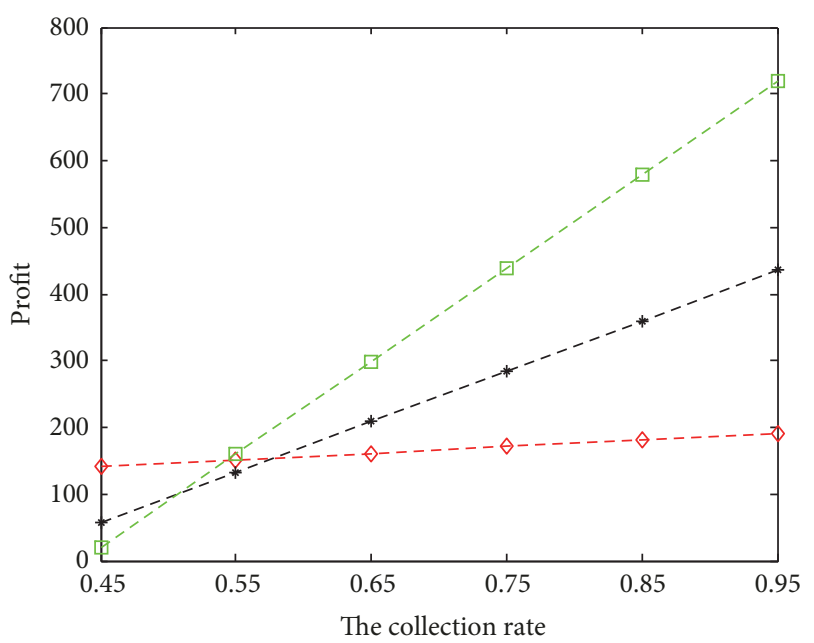

$$
\begin{aligned}
& -\diamond-\text { Only R-Channel } \\
& -*-\text { Both channels } \\
& -\boxminus-\text { Only D-Channel }
\end{aligned}
$$

FIgURE 4: The effect of the collection rate on profits.

can benefit most from $D$-Channel when the collection rate is large. The reasons that cause the profit growth lie in two aspects: one is the cost problem. The recycling process reduces the using of raw material and lowers the production cost. The other is that the increasing consumers create a great demand. Therefore, it makes an increase in profit.

Figure 5 shows that the profit in $R$-Channel decreases with the correlation, but it has nothing to do with the other two channels. This is because in the $R$-Channel a higher $\rho$ value implies the more demand variability. The manufacturer cannot make an accurate demand forecast, which means higher inventory risk for the manufacturer. Therefore, the higher inventory cost will cut the profit of the manufacturer.

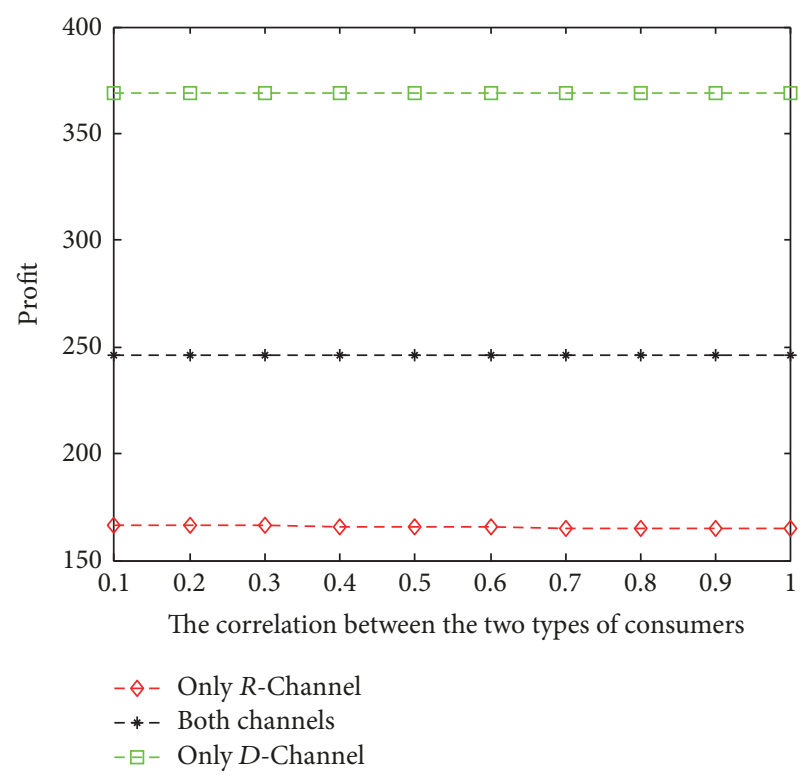

FIgURE 5: The effect of the correlation between the two types of consumers on profits.

\section{Conclusion}

This paper studies the channel strategies for the manufacturer. The market demand is a stochastic variable which brings difficulty for most profit by producing right good. The Internet environment, different types of consumers, and the stochastic demand of the market increase the complexity of the closed-loop supply chain. Consumers are not able to know the product valuation until they receive it. The manufacturer has three price options regarding the Internet channel: no Internet channel with a small discount, only Internet channel with a big discount, and dual channel with a moderate discount. After a thorough comparative analysis of the three cases, the manufacturer commits to a price scheme and product quantity of each channel in order to maximize his profit.

Our results indicate that loss-averse consumer has a major influence on the manufacturer's profit. An increase in loss-averse degree may benefit the manufacturer in both channels. When the acceptation of the D-Channel and the collection rate are higher or the standard deviation of consumer valuation and the loss-averse index are lower, the manufacturer is likely to be better in the D-Channel than in the two others.

We also analyze the effect of other parameters on the three scenarios. When we consider the effect of the correlation of the type $L$ and $N$ consumers, we observe that the manufacturer's profit decreases in $R$-Channel but this decrease is very little. It has only a small impact on the profit of the manufacturer. However, the demand variability and the collection rate become important for the manufacturer. They have a significant effect on the profit of the manufacturer.

Of course, the real word has many more and complex features which are not captured by our model. Consumers distinguish the remanufactured products from the 
new products. The primary consumers discount the value of the remanufactured products, and the manufacture is better offering price discrimination to maximize his profit. Hence, three aspects of the demand would be examined. The manufacturers competition can be considered. Our onestage model can be extended to a two-stage close-loop supply chain. The manufacturer may benefit from the low cost of the Internet channel, so he can attract more consumers to purchase through Internet by offering value added services. Also, the stock-out risk can be incorporated into our model in the future.

\section{Conflicts of Interest}

The authors declare that there are no conflicts of interest regarding the publication of this paper.

\section{Acknowledgments}

The authors are grateful to Professor Shu-yun Wang and Dr. Zhe Wang for their helpful comments and suggestions. They acknowledge the support of (1) a Project of Shandong Province Higher Educational Science and Technology Program (no. J17KA174), (2) the Fundamental Research Funds for the Central Universities (NP 2016303 and NS 2017057), (3) National Natural Science Foundation of China (no. 71672166 and no. 71372122), and (4) Funding of Jiangsu Innovation Program for Graduate Education (KYZZ16_0151).

\section{References}

[1] M. Fleischmann, J. M. Bloemhof-Ruwaard, R. Dekker, E. Van Der Laan, J. A. E. E. Van Nunen, and L. N. Van Wassenhove, "Quantitative models for reverse logistics: A review," European Journal of Operational Research, vol. 103, no. 1, pp. 1-17, 1997.

[2] V. D. R. Guide Jr., V. Jayaraman, R. Srivastava, and W. C. Benton, "Supply-chain management for recoverable manufacturing systems," Interfaces, vol. 30, no. 3, pp. 125-142, 2000.

[3] A. Atasu, M. Sarvary, and L. N. V. Wassenhove, "Remanufacturing as a marketing strategy," Management Science, vol. 54, no. 10, pp. 1731-1746, 2008.

[4] M. Denizel, M. Ferguson, and G. G. C. Souza, "Multiperiod remanufacturing planning with uncertain quality of inputs," IEEE Transactions on Engineering Management, vol. 57, no. 3, pp. 394-404, 2010.

[5] A. Shakourloo, A. Kazemi, and M. O. M. Javad, "A new model for more effective supplier selection and remanufacturing process in a closed-loop supply chain," Applied Mathematical Modelling, vol. 40, no. 23-24, pp. 9914-9931, 2016.

[6] C. C. Fang, M. H. Lai, and Y. S. Huang, "Production planning of new and remanufacturing products in hybrid production systems," Computers \& Industrial Engineering, 2017.

[7] E. V. D. Laan, The effects of remanufacturing on inventory control. Doctoral dissertation [Doctoral, thesis], Erasmus University, School of Management, Rotterdam, 1997.

[8] X. Gong and X. Chao, "Technical note-Optimal control policy for capacitated inventory systems with remanufacturing," Operations Research, vol. 61, no. 3, pp. 603-611, 2013.

[9] E. Ahmadzadeh and B. Vahdani, "A location-inventory-pricing model in a closed loop supply chain network with correlated demands and shortages under a periodic review system," Computers \& Chemical Engineering, vol. 101, pp. 148-166, 2017.

[10] R. C. Savaskan, S. Bhattacharya, and L. N. Van Wassenhove, "Closed-loop supply chain models with product remanufacturing," Management Science, vol. 50, no. 2, pp. 239-252, 2004.

[11] X. Hong, Z. Wang, D. Wang, and H. Zhang, "Decision models of closed-loop supply chain with remanufacturing under hybrid dual-channel collection," The International Journal of Advanced Manufacturing Technology, vol. 68, no. 5-8, pp. 1851-1865, 2013.

[12] Y. He, "Acquisition pricing and remanufacturing decisions in a closed-loop supply chain," International Journal of Production Economics, vol. 163, pp. 48-60, 2015.

[13] P. Yi, M. Huang, L. Guo, and T. Shi, "Dual recycling channel decision in retailer oriented closed-loop supply chain for construction machinery remanufacturing," Journal of Cleaner Production, vol. 137, pp. 1393-1405, 2016.

[14] Y. Liu and Z. K. Xiong, "Study of Direct Marketing and Distribution Marketing Channel of Remanufactured Product under Distributing New Product," Industrial Engineering Management, vol. 16, no. 4, pp. 40-45, 2011.

[15] K. Wang, Y. Zhao, Y. Cheng, and T.-M. Choi, "Cooperation or competition? Channel choice for a remanufacturing fashion supply chain with government subsidy," Sustainability, vol. 6, no. 10, pp. 7292-7310, 2014.

[16] W. Yan, Y. Xiong, Z. Xiong, and N. Guo, "Bricks vs. clicks: which is better for marketing remanufactured products?" European Journal of Operational Research, vol. 242, no. 2, pp. 434-444, 2015.

[17] Z. B. Wang, Y. Y. Wang, and J. C. Wang, "Optimal distribution channel strategy for new and remanufactured products," Electronic Commerce Research, vol. 16, no. 3, p. 27, 2016.

[18] J. Gao, X. Wang, Q. Yang, and Q. Zhong, "Pricing Decisions of a Dual-Channel Closed-Loop Supply Chain under Uncertain Demand of Indirect Channel," Mathematical Problems in Engineering, vol. 2016, Article ID 6053510, 2016.

[19] B. C. Giri, A. Chakraborty, and T. Maiti, "Pricing and return product collection decisions in a closed-loop supply chain with dual-channel in both forward and reverse logistics," Journal of Manufacturing Systems, vol. 42, pp. 104-123, 2017.

[20] S. S. Ahiska and E. Kurtul, "Modeling and analysis of a product substitution strategy for a stochastic manufacturing/remanufacturing system," Computers \& Industrial Engineering, vol. 72, no. 1, pp. 1-11, 2014.

[21] H. Sun, Y.-T. Wu, and Q.-L. Da, "Pricing and coordinating a closed-loop supply chain with loss-averse retailer and pricedependent stochastic demand," Kongzhi yu Juece/Control and Decision, vol. 29, no. 10, pp. 1885-1892, 2014.

[22] L. J. Zeballos, C. A. Méndez, A. P. Barbosa-Povoa, and A. Q. Novais, "Multi-period design and planning of closed-loop supply chains with uncertain supply and demand," Computers \& Chemical Engineering, vol. 66, pp. 151-164, 2014.

[23] X. Li, Y. Li, and X. Cai, "Remanufacturing and pricing decisions with random yield and random demand," Computers \& Operations Research, vol. 54, pp. 195-203, 2015.

[24] W. K. Chiang, D. Chhajed, and J. D. Hess, "Direct marketing, indirect profits: a strategic analysis of dual-channel supplychain design," Management Science, vol. 49, no. 1, pp. 1-20, 2003.

[25] G. W. Hua, S. Y. Wang, and T. C. E. Cheng, "Price and lead time decisions in dual-channel supply chains," European Journal of Operational Research, vol. 205, no. 1, pp. 113-126, 2010. 
[26] B. Li, P.-W. Hou, P. Chen, and Q.-H. Li, "Pricing strategy and coordination in a dual channel supply chain with a risk-averse retailer," International Journal of Production Economics, vol. 178, pp. 154-168, 2016.

[27] A. Tversky and D. Kahneman, "Loss aversion in riskless choice: a reference-dependent model," The Quarterly Journal of Economics, vol. 107, no. 4, pp. 1039-1061, 1991.

[28] H. Sibly, "Loss averse customers and price inflexibility," Journal of Economic Psychology, vol. 23, no. 4, pp. 521-538, 2002.

[29] P. Heidhues and B. Koszegi, "The impact of consumer loss aversion on pricing," Markets and Political Economy Working Paper No. SP II, p. 17, 2004.

[30] M. Abdellaoui, H. Bleichrodt, and C. Paraschiv, "Loss aversion under prospect theory: a parameter-free measurement," Management Science, vol. 53, no. 10, pp. 1659-1674, 2007.

[31] E. G. J. Won, “The Effect of Consumers' Loss Aversion on Pioneering Advantage," Management Science Financial Engineering, vol. 17, no. 1, p. 18, 2011.

[32] S. H. Kim and J. Lee, "Firm behavior under consumer loss aversion," Seoul Journal of Economics, vol. 27, pp. 171-186, 2014.

[33] A. Rosato, "Selling substitute goods to loss-averse consumers: limited availability, bargains, and rip-offs," The RAND Journal of Economics, vol. 47, no. 3, pp. 709-733, 2016. 


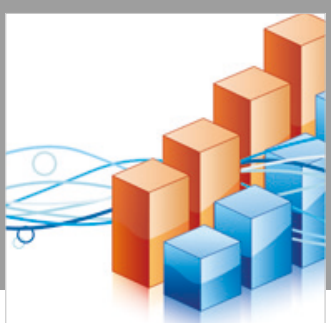

Advances in

Operations Research

\section{-n-m}
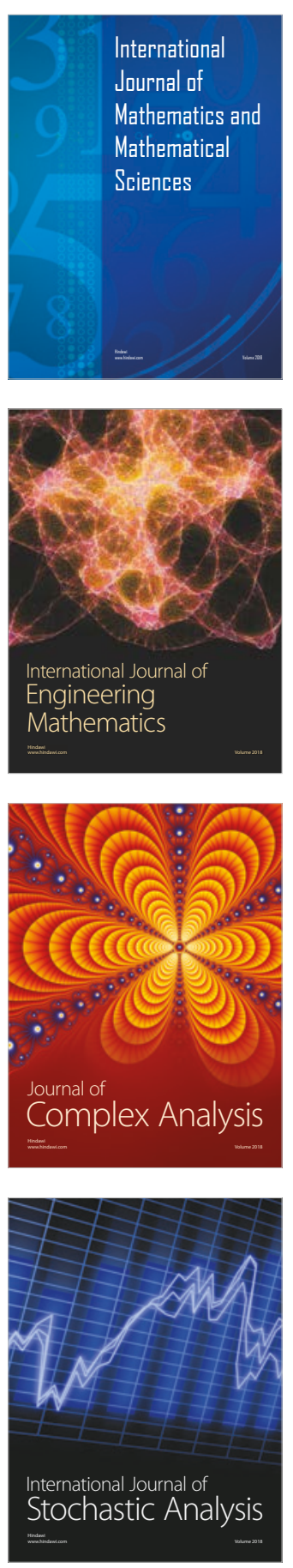
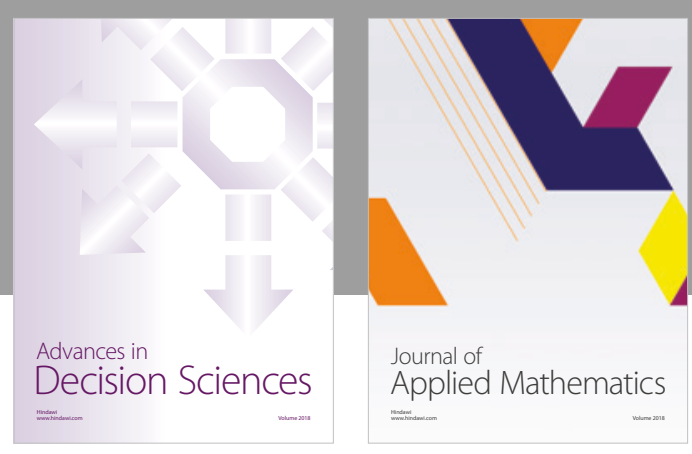

Journal of

Applied Mathematics
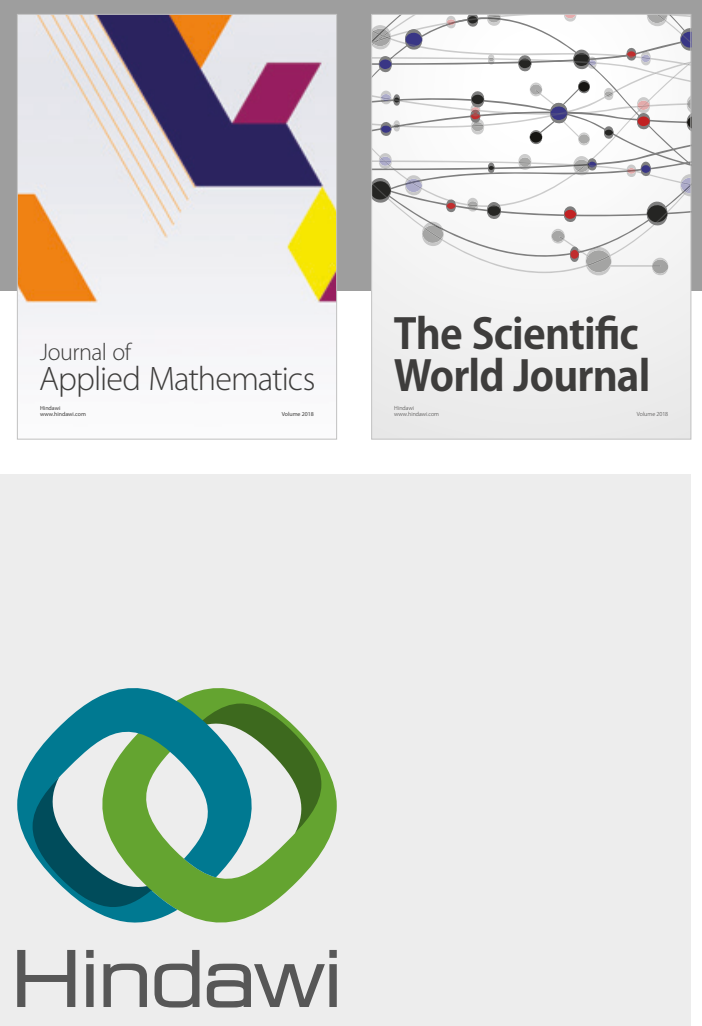

Submit your manuscripts at

www.hindawi.com

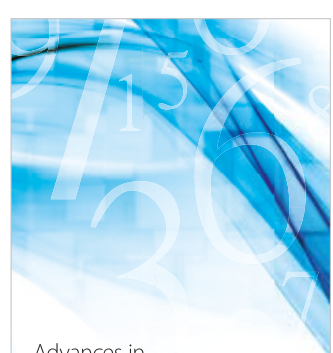

Advances in
Numerical Analysis
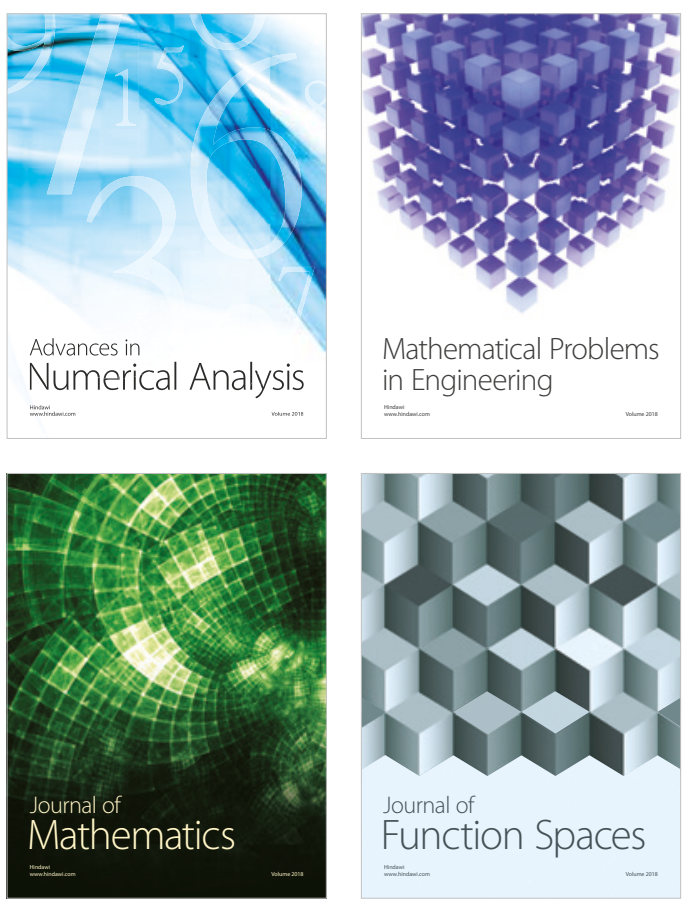

Mathematical Problems in Engineering

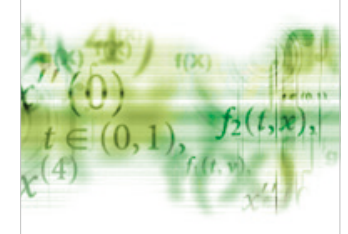

International Journal of

Differential Equations

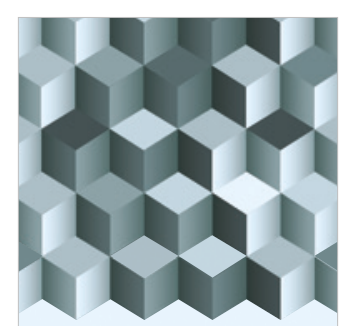

Journal of

Function Spaces

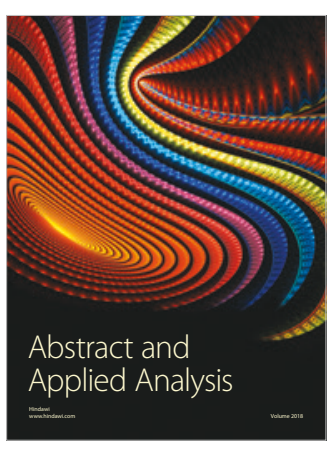

The Scientific

World Journal

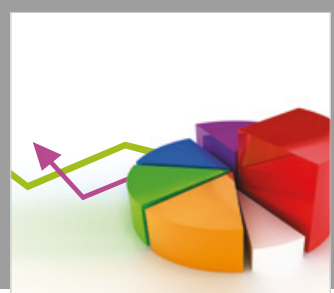

Journal of

Probability and Statistics
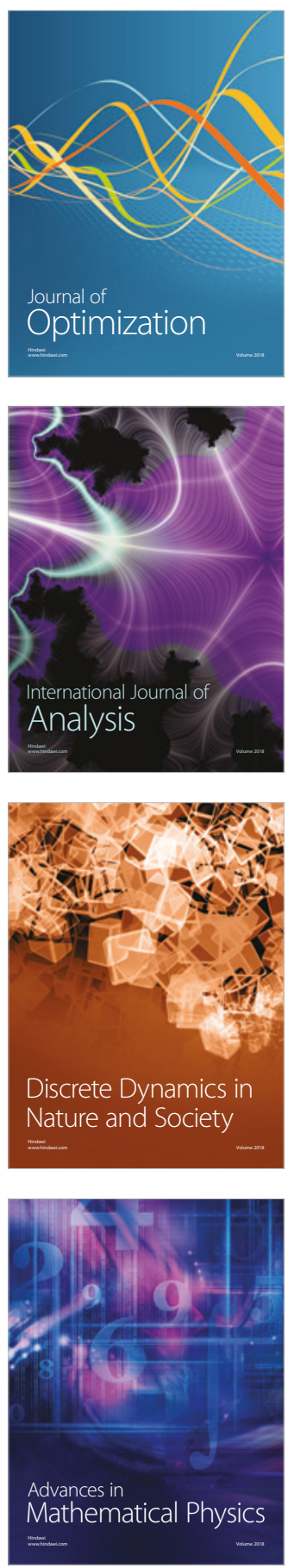